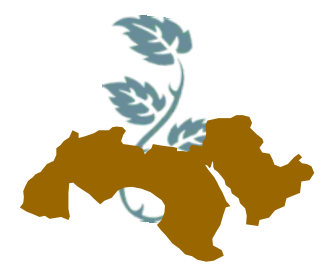

\title{
RESIDUES OF IMIDACLOPRID AND MYCOLBUTANIL IN/ON GRAPE AND SOIL UNDER FIELD CONDITIONS
}

\author{
Abd El-Megeed ${ }^{1}$ M.I., Mohamed ${ }^{1}$ K.A., Hammad ${ }^{1}$ M.A., Naglaa M. Ebeed ${ }^{2}$ \\ and Shimaa M. Mohamed ${ }^{1}$
}

1- Plant Protection Dept., Fac. of Agric., Ain Shams Univ., P.O. Box 68, Hadayek Shobra11241, Cairo, Egypt

2- Genetic Dept., Fac. of Agric., Ain Shams Univ., P.O. Box 68, Hadayek Shobra11241, Cairo, Egypt

*Corresponding author: m_mgeed@yahoo.com

Keywords: Persistence, Degradation, Behavior, Imidacloprid, Myclobutanil, Residues, Grape, Soil

\section{ABSTRACT}

Persistence Vs degradation behavior of insecticide imidacloprid (35\% SC) and fungicide myclobutanil (24\% EC) in/on grape (leaves and fruits) and surrounding soil under canopy were investigated under field conditions. Leaves, fruits and soil samples were collected at 2 hours to 21 days after application at the recommended rate. QuEChERS method was used for extraction and clean-up and analyzed using HPLC and GC for imidacloprid and myclobutanil, respectively .The initial residue deposits, degradation percentages and/or, the parameters $\left(R L_{50}\right.$ and $\left.R L_{90}\right)$ and Pre Harvest Intervals (PHIs) of the targeted pesticides were the criteria of concern. Results revealed that, grape leaves retained higher initial amounts than fruits by about 5.07 and 1.34 times for imidacloprid and myclobutanil, respectively. As for $R L_{50}, R L_{90}$ and PHls values, imidacloprid showed 4.12 13.42 and 21.95 days and 5.13 ، 13.41 and 11.96 days on grape leaves and fruit, respectively. The corresponding calculated values were $4.71,9.38$ and 16.31days and 1.97, 9.14 and 14.90 days for myclobutanil on the same targeted samples, respectively. In addition, the grape fruits could be consumed safely after 12 and 15 days of treatment with imidacloprid and myclobutanil, respectively. On the other hand ، results indicated that the residue half life $\left(R L_{50}\right)$ values for the same targeted pesticides in soil were 11.56 and 15.74 days, respectively. In general, myclobutanil residues in soil recorded higher persistence levels than higher imidacloprid and on the contrary it showed less persistence in/on grape leaves and fruits.

\section{INTRODUCTION}

In general scope, the intensive and increase use of pesticides as a response to the continued efforts to intensity crop production has consequently become invertible and controversial issue resulting in serious problems as regard to the target pests and adverse effects against environmental non-target organisms and human health. Nowadays, the cultivation of grapes is widely spread around the world with an estimated surface area of 7.6 million hectares in 2014 (Grimalt and Dehouck 2016). Grapes a nutritionally important fruit crop of international trade significance are consumed both as fresh and processed products (Sinha et al 2012).

Imidacloprid is a relatively new insecticide with high activity against sucking insects. It is the most use systemic insecticide in the world in more than 100 countries (Bonmatin et al 2003) especially on grapes, Myclobutanil belongs to conazole fungicide, it is a systemic fungicide with preventive, curative and eradicant properties for grape fungi. On the other hand environmental fate is the back bone of hazard evaluation components in risk assessment system. However, the wide spectrum of contamination with pesticide residues as one of the 
main elements of our ecosystem and environment was reported by many investigators (Shady et al 2000).

A wide range of factors determine the fate of pesticides in the environment. These include chemical characteristics (vapor pressure, solubility, and adsorptive behavior), environmental characteristics (precipitation, temperature and soil, sediment and water characteristics) and agricultural practices (cropping practices, application methods, timing of application and landscape). Risk assessment regulatory decisions relating to the approval of pesticides are based on whether the predicted levels of exposure following the proposed or approved use are safe to consumers, operators and the environment. Although environmental exposure depends largely on the behavior of the pesticide in the field, this cannot be defined simply by factors such as degradation rate and mobility. It has been reported that soil $\mathrm{pH}$, moisture, temperature and pesticide concentration are the most important factors affecting the persistence of pesticides (Sundaram Baskaran et al 1999). These factors are highly dependent on environmental conditions such as temperature, rainfall and soil properties and therefore can only be quantified for specific laboratory or field studies. Degradation can include such processes as hydrolysis, photolysis, microbial metabolism etc. Movement reduces the concentration in the treated compartment but transports residues to untreated compartments, e.g. from plant surface to soil or soil to water. A stepwise or tiered approach allows an efficient selection of tests essential to each individual risk assessment (Shady et al $\mathbf{2 0 0 0}$ and Sinha et al 2012).

Therefore, the present work was conducted to determine the residues of the insecticide imidacloprid and fungicide myclobutanil on grape (leaves and fruits) and surrounding soil under canopy as well as determination of its initial residue deposits, degradation percentages and/or the parameters $\left(R L_{50}\right.$ and $\left.R L_{90}\right)$ and pre harvest intervals (PHIs). This will help to avoid their hazards to consumers.

\section{MATRIAL AND METHODS}

\section{1- Pesticides selected for this study}

Two pesticides in their soluble concentrate (35\% SC) and emulsifiable concentrate (24\% EC $24 \%$ EC) formulations were selected throughout the present study. These pesticides are used extensively in Egypt for controlling target key insects and fungus attacking grape crops and other Egyptian cultivations,. Rates of pesticides application were chosen on the basis of recommended rates on grapes.

\section{2- Field experiments and sampling}

The research was conducted in summer season of 2015 at a private farm of grape (varity vitis vinifera (superior)) located at $74 \mathrm{~km}$ AlexandriaCairo, desert road, Egypt. The experiments were planted in a randomized complete block design. For each tested pesticides, four plots were done (25 Square meters each) and four replicates were carried out for each treatment. The targeted plots were sprayed with imidacloprid 35\% SC and myclobutanil $24 \%$ EC by using tractor sprayer motor (600 liter) fitted with one nozzle Control plots were left un-sprayed. The rates of recommended appli-

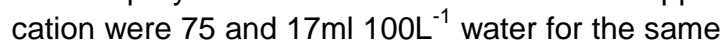
mentioned pesticides, respectively. Samples of grape (leaves and fruits) and surrounding soil were taken randomly from each plot in triplicates at two hour, 1, 3, 7, 10, 13, 16 and 21 days after application. Then, samples were transported immediately in ice box to the Laboratory and kept in freezer at $20^{\circ} \mathrm{C}$ till pesticide residues analysis.

\section{3- Pesticides residues analysis}

Stock solutions $\left(100 \mu \mathrm{g} \mathrm{gm}{ }^{-1}\right)$ of imidacloprid and myclobutanil were prepared in toluene. A series of gradient concentrations, i.e. $0.5,1,2$, and $2.5 \mu \mathrm{g} \mathrm{gm}^{-1}$ of analytical standard of tested pesticides in toluene were prepared and injected at the following gas chromatography (GC) and high performance liquid chromatography (HPLC) operating conditions. The resulted peak area was plotted against $\mu \mathrm{g} \mathrm{gm}^{-1}$ of each concentration and the standard calibration curve was established.

Grape samples (leaves and fruits) were extracted and cleaned up according to the methods adopted by QuEChERS Anastassiades et al 2003). A homogenized grape leaves and fruits samples $(10 \mathrm{gm})$ were taken in to a centrifuge tube $(50 \mathrm{ml})$. Fifteen milliliters of acetonitrile containing $1.0 \%$ acetic acid was transferred to the centrifuge tube and vigorously shaken for $1 \mathrm{~min}$. Then, $4 \mathrm{gm}$ magnesium sulfate anhydrous, and $1 \mathrm{gm}$ sodium acetate were added, and then the mixture was shaken vigorously for $5 \mathrm{~min}$. The mixture was centrifuged at $3000 \mathrm{rpm}$ for $5 \mathrm{~min}$. Five milliliter of the supernatant was transferred to centrifuge tube $(15 \mathrm{ml})$ and shaken with $50 \mathrm{mg}$ primary secondary amine (PSA), 10mg graphitized carbon black and $150 \mathrm{mg}$ magnesium sulfate. Thereafter, the tube was centrifuged for $10 \mathrm{~min}$ at $6000 \mathrm{rpm}$. 

Field Conditions

On the other hand, soil samples were extracted and cleaned up according to the method adopted by (Deng et al 2010). One kilogram of soil sample was sieved and mixed then $20 \mathrm{gm}$ was placed into a $200 \mathrm{ml}$ extraction bottle and $60 \mathrm{ml}$ of solvent mixture (methanol/water 1:1) was added then left for $30 \mathrm{~min}$. The extracts were partitioned with dichloromethane three sequentially $(3 \times 20 \mathrm{ml})$ in the presence of $50 \mathrm{ml} 2 \%$ sodium sulfate solution. The combined dichloromethane extracts were filtered using filter paper (Watman ${ }^{\mathrm{TM}}$ no4) and concentrated to dryness. The extract were dissolved in $3 \mathrm{ml}$ n-hexane - acetone (9:1 v/v) and subjected to SPE (A weak amino - exchange primary secondary amin).

One $\mathrm{ml}$ of all cleaned samples was filtered using 0.45 um filter and transferred into an injection vial for determination by HPLC and GC. In this respect, the cleaned samples of imidacloprid was taken for analysis by HPLC with an Agilent 1100 HPLC system (USA), with quaternary pump, auto sampler injector, thermostat compartment for the column, and photodiode array detector $(270 \mathrm{~nm}$ Wave length). The chromatographic column was Zorbax C8 SB (250 x 4.6mm, 5um film thickness). The column was kept at room temperature. Flow rate of mobile phase (acetonitrile/methanol, 80:20, $\mathrm{v} / \mathrm{v})$ was $0.8 \mathrm{ml} \mathrm{min}^{-1}$, and injection volume was $20 \mu \mathrm{L}$. In addition, the cleaned samples of myclobutanil were taken for analysis by Agilent GC HP $6890 \mathrm{~N}$ network GC system equipped with micro
ECD detector. The column was PAS-1701(30m x $0.53 \mathrm{~mm}$ I.d.x1um film. Injector, column and detector temperatures were 250,220 and $300^{\circ} \mathrm{C}$, respectively. A nitrogen gas flow rate was $3 \mathrm{ml} \mathrm{min}^{-1}$ and injection volume was $20 \mu \mathrm{L}$. These conditions resulted in good separations and high sensitivity was obtained with retention times 6.8 and $2.6 \mathrm{~min}$ for imidacloprid and myclobutanil, respectively.

\section{4- Recovery samples and statistical analysis}

To estimate the recovery percentages, known quantities of imidacloprid and myclobutanil were added to check samples of grape (leaves and fruits) and soil at four levels $(0.5,1,2$ and $2.5 \mu \mathrm{g}$ $\left.\mathrm{gm}^{-1}\right)$, Extraction and clean-up processes were carried out as described above. The average recovery percentages in fruits and leaves for the two targeted pesticides were 81.8, 89.6, 79.8 and $91.5 \%$ (leaves) and $75.3,83,88.5$ and $90 \%$ (fruits) and $93.5,91.1,86.5$ and 88.5 (soil)/imidacloprid and $93.5,89.7,90.3$ and $87.3 \%$ (leaves) and 89.2 , $90.5,91.8$ and $95.8 \%$ (fruits) and $91.8,79.9,80.8$ and 89.5 (soil)/myclobutanil for four tested levels, respectively (Table 1 ). The obtained results were corrected according to their mean of recovery percentages. The degradation constant $(\mathrm{K})$ and degradation periods $\left(R L_{50}\right.$ and $\left.R L_{90}\right)$ of each pesticide were calculated as follows: rate of degradation $\mathrm{K}=$ $2.303 \times$ slope, and the half-life period $R L_{50}=0.693 / K$ (Gomaa and Belal 1975).

Table 1. Recovery percentages (\%) of imidacloprid and myclobutanil pesticides from spiked samples of grape (leaves and fruits) and soil

\begin{tabular}{|c|c|c|c|c|c|c|c|c|}
\hline $\begin{array}{c}\text { Spiked } \\
\text { samples }\end{array}$ & \multicolumn{4}{|c|}{ Imidacloprid } & \multicolumn{4}{c|}{ Myclobutanil } \\
\hline Leaves & $81.8^{\mathrm{a}}$ & $89.6^{\mathrm{b}}$ & $79.8^{\mathrm{C}}$ & $91.5^{\mathrm{d}}$ & $93.51^{\mathrm{a}}$ & $89.70^{\mathrm{b}}$ & $90.3^{\mathrm{c}}$ & $87.31^{\mathrm{d}}$ \\
Fruits $^{\mathrm{a}}$ & $75.3^{\mathrm{a}}$ & $83.04^{\mathrm{b}}$ & $88.5^{\mathrm{c}}$ & $90.03^{\mathrm{d}}$ & $89.17^{\mathrm{a}}$ & $90.53^{\mathrm{b}}$ & $91.81^{\mathrm{c}}$ & $95.77^{\mathrm{d}}$ \\
Soil & $93.5^{\mathrm{a}}$ & $91.06^{\mathrm{b}}$ & $86.5^{\mathrm{c}}$ & $88.5^{\mathrm{d}}$ & $81.82^{\mathrm{a}}$ & $79.93^{\mathrm{b}}$ & $80.77^{\mathrm{c}}$ & $89.5^{\mathrm{d}}$ \\
\hline
\end{tabular}

\section{RESULTS AND DISCUSSION}

\section{Residues of imidacloprid in/on grape (leaves and fruits)}

Residues and degradation percentages of insecticide imidacloprid in/on grape (leaves and fruits) are illustrated in Table (2) and Figs. (1 and 2). The initial residue deposits on grape leaves and fruits two hours after treatment were 35.66 and
$7.04 \mathrm{mg} \mathrm{kg}^{-1}$, respectively. These amounts decreased to 28.16 and $5.92 \mathrm{mg} \mathrm{kg}^{-1}$ one day after the application indicating degradation percentages of 21.04 and $15.90 \%$, respectively. Residues of imidacloprid in/on grape (leaves and fruits) were gradually decreased to $19.52,11.84,6.40,5.12$, 2.88 and ND mg kg ${ }^{-1}$ corssponding degradation percentages of $45.26,66.80,82.05,85.64,91.92$ and $\approx 100 \%$ (leaves), and $4.32,2.44,1.64,1.28$, 0.32 and ND mg kg ${ }^{-1}$ corssponding degradation 
percentages of $38.64,65.34,76.71,81.82$, 95.45 and $\approx 100 \%$ (fruits) after 3, 7, 10, 13, 16 and 21 days of application, respectively. Examination of the considered criteria represented by the established regression lines, i.e. slope, degradation constant $(\mathrm{K})$ and $R \mathrm{~L}_{50}, \mathrm{R} \mathrm{L}_{90}$ proved significant differences in persistence behaviour of the targeted pesticides. The imidacloprid degradation constant (K) values are 0.152 and 0.169 in/on grape (leaves and fruits), respectively. As for $R L_{50}, R L_{90}$ and PHIs values, imidacloprid showed 4.12, 13.42 and 21.95 days and 5.13, 13.41 and 11.96 days in/on grape leaves and fruits, respectively. These results indicated that the same degradation behavior of imidacloprid insecticide in/on grape leaves and fruits. Data in the same table indicated that despite of the low residue half-lifes for imidacloprid in grape fruits (5.13 days), it can be consumed safely after 12 days of treatment, concerning health aspects;. The maximum residue limit (MRL) of imidacloprid residues in/on grape according of Codex Aimentarias Commission (2013) was $1 \mathrm{mg} \mathrm{kg}^{-1}$.

Table 2. Residues of imidacloprid detected in/on grape (leaves and fruits).

\begin{tabular}{|c|c|c|c|c|c|c|}
\hline \multirow[b]{2}{*}{$\begin{array}{l}\text { Days after } \\
\text { treatment }\end{array}$} & \multicolumn{3}{|c|}{ Leaves } & \multicolumn{3}{|c|}{ Fruits } \\
\hline & $\begin{array}{c}\text { residues } \\
\mathrm{mg} \mathrm{kg}^{-1}\end{array}$ & $\begin{array}{c}\text { Degradation } \\
\%\end{array}$ & $\begin{array}{c}\text { Persistence } \\
\%\end{array}$ & $\begin{array}{c}\text { residues } \\
\mathrm{mg} \mathrm{kg}^{-1}\end{array}$ & $\begin{array}{c}\text { Degradation } \\
\%\end{array}$ & $\begin{array}{c}\text { Persistence } \\
\%\end{array}$ \\
\hline $\begin{array}{l}\text { Initial } \\
\text { (2 hrs) }\end{array}$ & 35.66 & - & 100 & 7.04 & - & 100 \\
\hline 1 & 28.16 & 21.04 & 78.96 & 5.92 & 15.90 & 84.09 \\
\hline 3 & 19.52 & 45.26 & 54.74 & 4.32 & 38.64 & 61.36 \\
\hline 7 & 11.84 & 66.80 & 33.20 & 2.44 & 65.34 & 34.66 \\
\hline 10 & 6.40 & 82.05 & 17.95 & 1.64 & 76.71 & 23.30 \\
\hline 13 & 5.12 & 85.64 & 14.36 & 1.28 & 81.82 & 18.18 \\
\hline 16 & 2.88 & 91.92 & 8.08 & 0.32 & 95.45 & 4.55 \\
\hline 21 & ND & $\approx 100$ & 0.00 & ND & $\approx 100$ & 0.00 \\
\hline $\mathrm{K}$ & \multicolumn{3}{|c|}{0.152} & \multicolumn{3}{|c|}{0.169} \\
\hline $\mathrm{RL}_{50}$ & \multicolumn{3}{|c|}{4.12} & \multicolumn{3}{|c|}{5.13} \\
\hline $\mathrm{RL}_{90}$ & \multicolumn{3}{|c|}{13.42} & \multicolumn{3}{|c|}{13.41} \\
\hline $\mathrm{PHI}$ & \multicolumn{3}{|c|}{21.95} & \multicolumn{3}{|c|}{11.96} \\
\hline
\end{tabular}

ND: Not detected under limit of detection $\left(0.006 \mathrm{mg} \mathrm{kg}^{-1}\right)$.

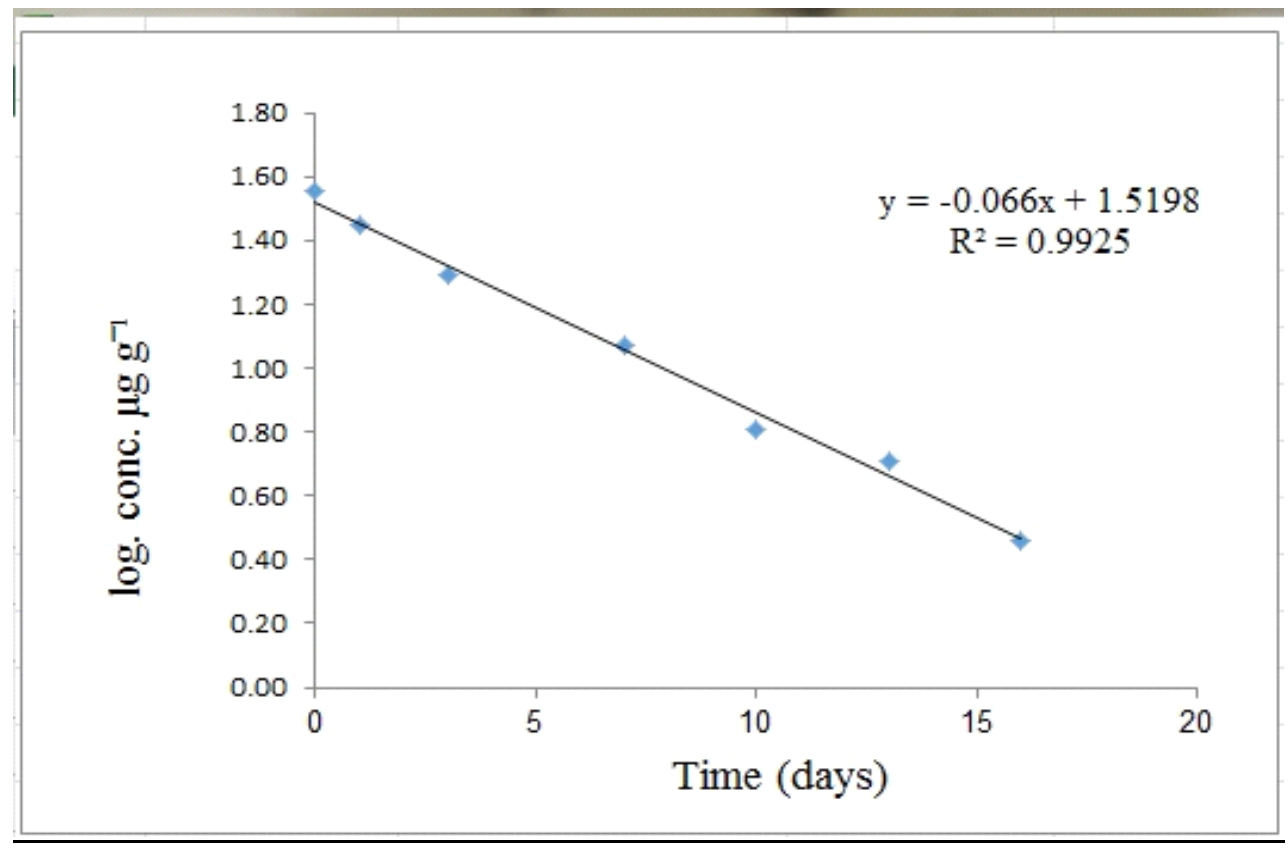

Fig. 1. Log. Residue - day regression lines of imidacloprid in/on grape leaves 


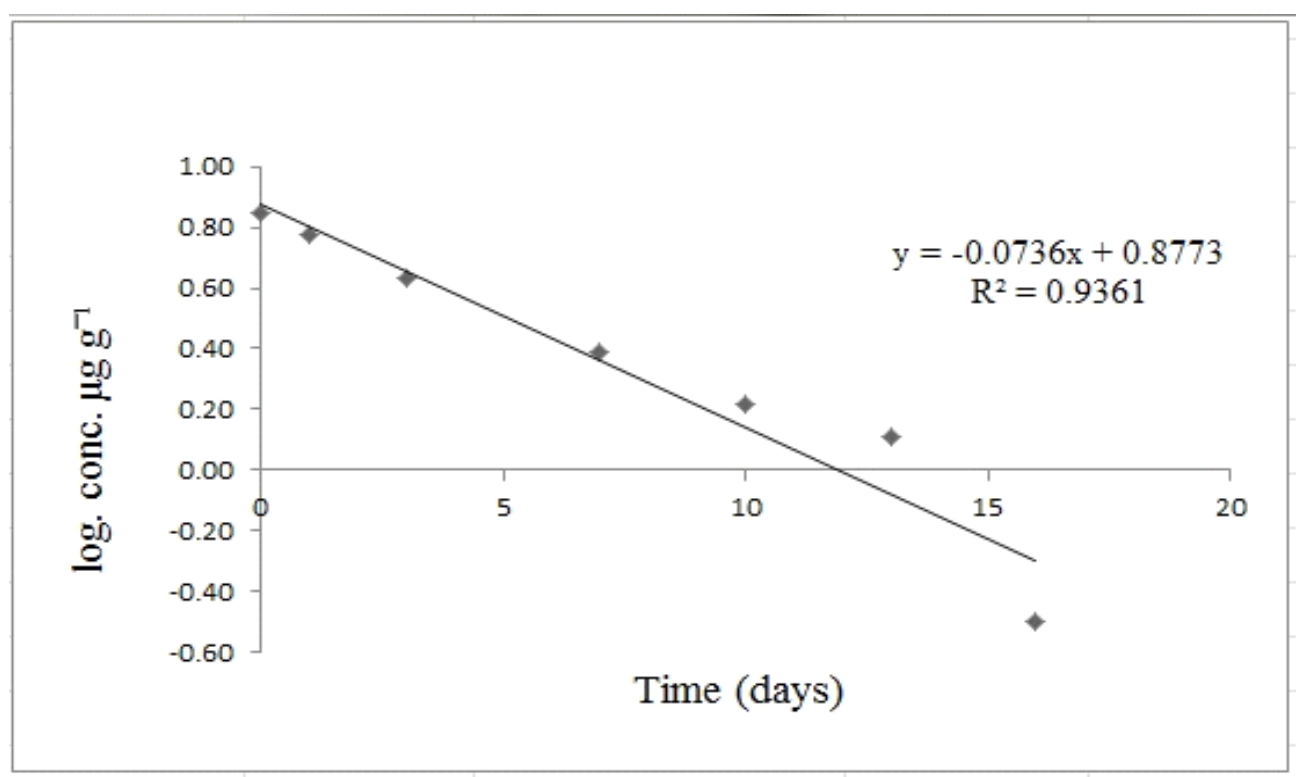

Fig. 2. Log. Residue - day regression lines of imidacloprid in/on grape fruits

\section{Residues of myclobutanil in/on grape (leaves and fruits)}

Residues and degradation percentages of fungicide myclobutanil in/on grape (leaves and fruits) are shown in Table (3) and Figs. (3 and 4). The initial residue deposits, determined on grape leaves and fruits two hours after treatment were 66.32 and $49.40 \mathrm{mg} \mathrm{kg}^{-1}$, respectively. These amounts decreased to 54.14 and $35.25 \mathrm{mg} \mathrm{kg}^{-1}$ one day recording degradation percentages of 18.36 and $28.64 \%$, respectively. Myclobutanil residues in/on grape (leaves and fruits) were gradually decreased to reach 40.15, 28.65, 12.09, 6.26, 0.85 and $0.11 \mathrm{mg} \mathrm{kg}^{-1}$ corssponding degradation percentages of $39.46,56.80,81.77,90.56,98.71$ and $99.83 \%$ (leaves), and 15.86, 11.73, 3.95, 1.73, 0.63 and ND mg kg-1 corresponding degradation percentages of $67.89,76.25,92.00,96.49,98.72$ and $\approx 100 \%$ (fruits) after $3,7,10,13,16$ and 21 days of application, respectively. Examination of the considered criteria represented by the established regression lines, i.e. slope, degradation constant $(\mathrm{K})$ and $R L_{50}, R L_{90}$ proved significant differences in persistence behaviour of the targeted pesticides. The myclobutanil degradation constant (K) values are 0.289 and 0.258 in/on grape (leaves and fruits), respectively. As for $R L_{50}, R L_{90}$ and PHIs values, myclobutanil showed 4.71, 9.38 and 16.31days and $1.97,9.14$ and 17.25 days in/on grape leaves and fruits, respectively. These results indicated that the myclobutanil fungicide was degraded higher in grape fruits than that in leaves. Data in the same table indicated that despite of the low residue half-lives for myclobutanil in grape fruits (1.97 days), it can be consumed safely after 14.90 days of treatment, concerning health aspects,. The maximum residue limit (MRL) of myclobutanil residues in/on grape according of Codex Aimentarias Commission (2013) was $1 \mathrm{mg} \mathrm{kg}^{-1}$.

The above mentioned results (Tables 2 and 3 and Figs. 1 - 4) indicate the important role of pesticide type in determining initial deposits as well as residues pattern of the imidacloprid and myclobutanil in/on grape fruits. The fungicide myclobutanil showed the highest intial deposit (66.32 and 49.40 $\mathrm{mg} \mathrm{kg}^{-1}$ ) than the insecticide imidacloprid (35.66 and $7.04 \mathrm{mg} \mathrm{kg}^{-1}$ ) in/on grape (leaves and fruits), respectively. An opposite trend was obtained with residues degradation pattern, as indicated from $\mathrm{RL}_{50}$ and $R \mathrm{~L}_{90}$ values. Myclobutanil showed rapid decline of residues while imidacloprid was the least degradable compound. The $R L_{50}$ and $R L_{90}$ values reached 4.71 and 9.38 days (leaves) and 1.97 and 9.14 days (fruits)/myclobutanil and 4.12 and 13.42 days (leaves) and 5.13 and 13.41 days (fruits)/imidacloprid, respectively. It is interesting to notice that, degradation percentages in residues were higher in grape fruits as compared with leaves; especially with myclobutanil compared with imidacloprid residues. 
These differences in the loss of the initial residue deposits in leaves and fruits may be due to increase in growth rate of fruit which dilute the residue uptake in fruits, differences in pesticide chemical structure and may be also reflecting the titer of metabolizing enzyme. The figures of the rate of degradation as well as the half - life support this phenomenon, the figures of the rate of degradation in case of fruits are higher than those of leaves, and where as the inverse case could be observed with the figures of half - lives (Romeh and Hendawi, 2014; Cherukuri et al 2015; Sleem 2015; Ali, et al 2016 and Ramadan et al 2016 and Shalaby, 2016).

In addition, the initial amounts of each pesticide in leaves were much higher than those in grape fruits by about 5.07 and 1.34 times of imidacloprid and myclobutanil, respectively. Such differences may be due to pesticide chemical structure and the differences in the area, morphology and chemistry of the recipient two surfaces. Many investigators recorded that lower content of pesticide residues were determined on fruits compared with leaves on several vegetable and field crops (Ali, et al 2016 and Ramadan et al 2016 and Shalaby, 2016).

On the other hand, to estimate pre-harvest interval (PHI) and according to maximum residue limits (MRLs) which recorded $1 \mathrm{mg} \mathrm{kg}^{-1}$ for the two pesticides. This indicates that $\mathrm{PHI}$ of 11.96 and
14.90 days should be considered before human consumption of grape fruits contaminated with imidacloprid and myclobutanil residues, respectively. It is worthy mentioning to notice the long PHIs of the targeted pesticides prior to human consumption. The finding results concerning the residues of insecticide imidacloprid and fungicide myclobutanil in/on grape leaves and fruits are in harmony with few research workers, Mohapatra, et al (2011) showed that, initial residue deposit of imidacloprid on grape berries following treatment of Confidor 200SL at the recommended and double the recommended dose of 80 and $160 \mathrm{~g}$ a.i. ha ${ }^{-1}$ were 0.74 and $1.26 \mathrm{mg} \mathrm{kg}^{-1}$, respectively. Residues remained in the fruits up to 60 days but at a low level of 0.056 and $0.108 \mathrm{mg} \mathrm{kg}^{-1}$. The residues dissipated with the half-life of 16.6 days for both treatments. The pre-harvest interval (PHI) recommended for safe human consumption of grape berries is 60 days. Residues of imidacloprid in grape berries and soil at harvest (105 days after the last treatment) were observed to be below detectable limit of $0.05 \mathrm{mg} \mathrm{kg}^{-1}$ for both treatments. In another study, imidacloprid can be degraded in plants with the main breakdown products of a monohydroxy metabolite, imidacloprid guanidine, imidacloprid olefin a monoglucoside of 6chloropicolyl alcohol (Miles, Inc., 1992).

Table 3. Residues of myclobutanil detected in/on grape (leaves and fruits).

\begin{tabular}{|c|c|c|c|c|c|c|}
\hline \multirow{2}{*}{$\begin{array}{c}\text { Days } \\
\text { after } \\
\text { treatment }\end{array}$} & \multicolumn{3}{|c|}{ Leaves } & \multicolumn{3}{|c|}{ Fruits } \\
\hline & $\begin{array}{l}\text { residues } \\
\mathrm{mg} \mathrm{kg}^{-1}\end{array}$ & $\begin{array}{c}\text { Degradation } \\
\% \\
\end{array}$ & $\begin{array}{c}\text { Persistence } \\
\% \\
\end{array}$ & $\begin{array}{l}\text { residues } \\
\mathrm{mg} \mathrm{kg}^{-1}\end{array}$ & $\begin{array}{c}\text { Degradation } \\
\% \\
\end{array}$ & $\begin{array}{c}\text { Persistence } \\
\% \\
\end{array}$ \\
\hline $\begin{array}{l}\text { Initial } \\
\text { (2 hrs) }\end{array}$ & 66.32 & - & 100.00 & 49.40 & - & 100.00 \\
\hline 1 & 54.14 & 18.36 & 81.63 & 35.25 & 28.64 & 71.36 \\
\hline 3 & 40.15 & 39.46 & 60.53 & 15.86 & 67.89 & 32.10 \\
\hline 7 & 28.65 & 56.80 & 43.19 & 11.73 & 76.25 & 23.74 \\
\hline 10 & 12.09 & 81.77 & 18.22 & 3.95 & 92.00 & 7.99 \\
\hline 13 & 6.26 & 90.56 & 9.43 & 1.73 & 96.49 & 3.50 \\
\hline 16 & 0.85 & 98.71 & 1.28 & 0.63 & 98.72 & 1.27 \\
\hline 21 & 0.11 & 99.83 & 0.16 & ND & $\approx 100$ & 0.00 \\
\hline $\mathrm{K}$ & \multicolumn{3}{|c|}{0.289} & \multicolumn{3}{|c|}{0.258} \\
\hline $\mathrm{RL}_{50}$ & \multicolumn{3}{|c|}{4.71} & \multicolumn{3}{|c|}{1.97} \\
\hline $\mathrm{RL}_{90}$ & \multicolumn{3}{|c|}{9.38} & \multicolumn{3}{|c|}{9.14} \\
\hline $\mathrm{PHI}$ & \multicolumn{3}{|c|}{16.31} & \multicolumn{3}{|c|}{14.90} \\
\hline
\end{tabular}

ND: Not detected under limit of detection $\left(0.006 \mathrm{mg} \mathrm{kg}^{-1}\right)$. 


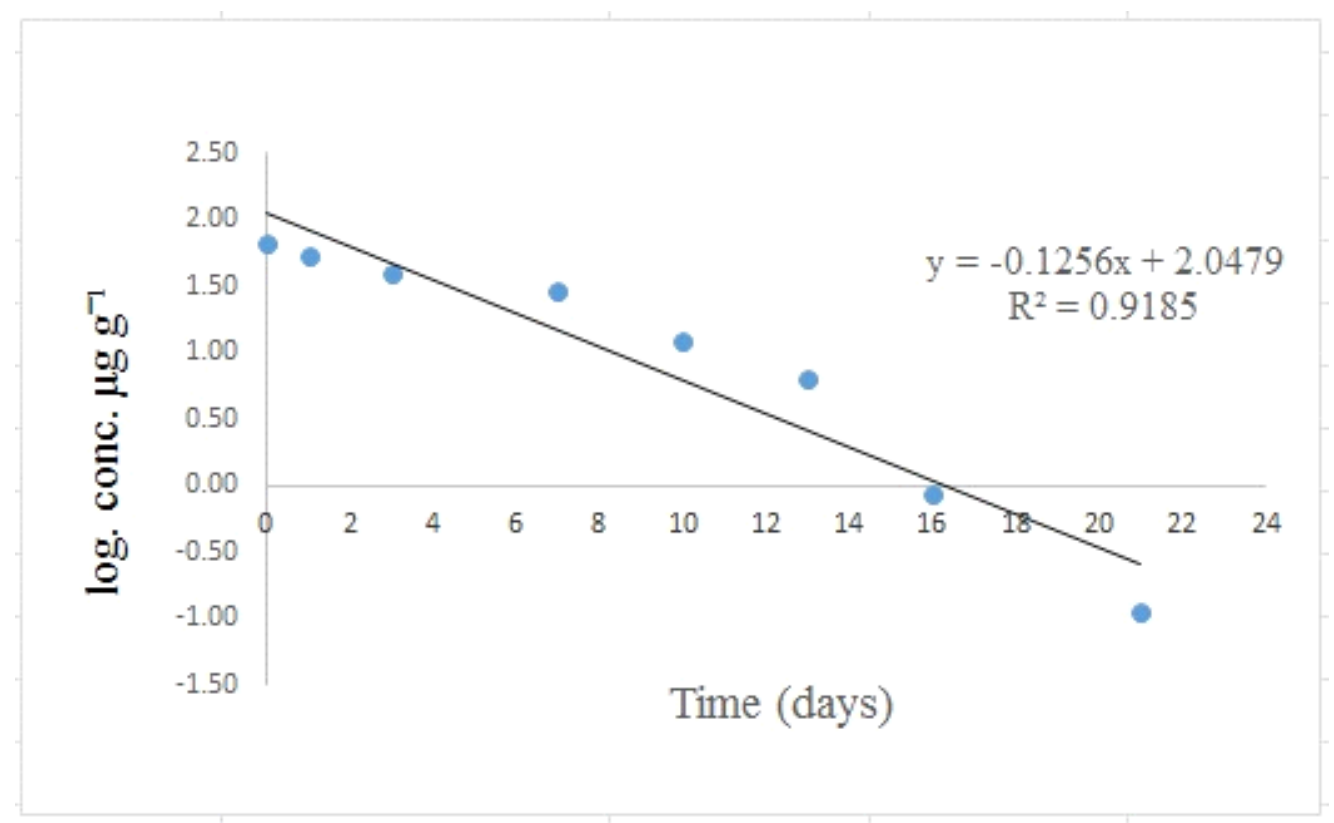

Fig. 3. Log. Residue - day regression lines of myclobutanil in/on grape leaves

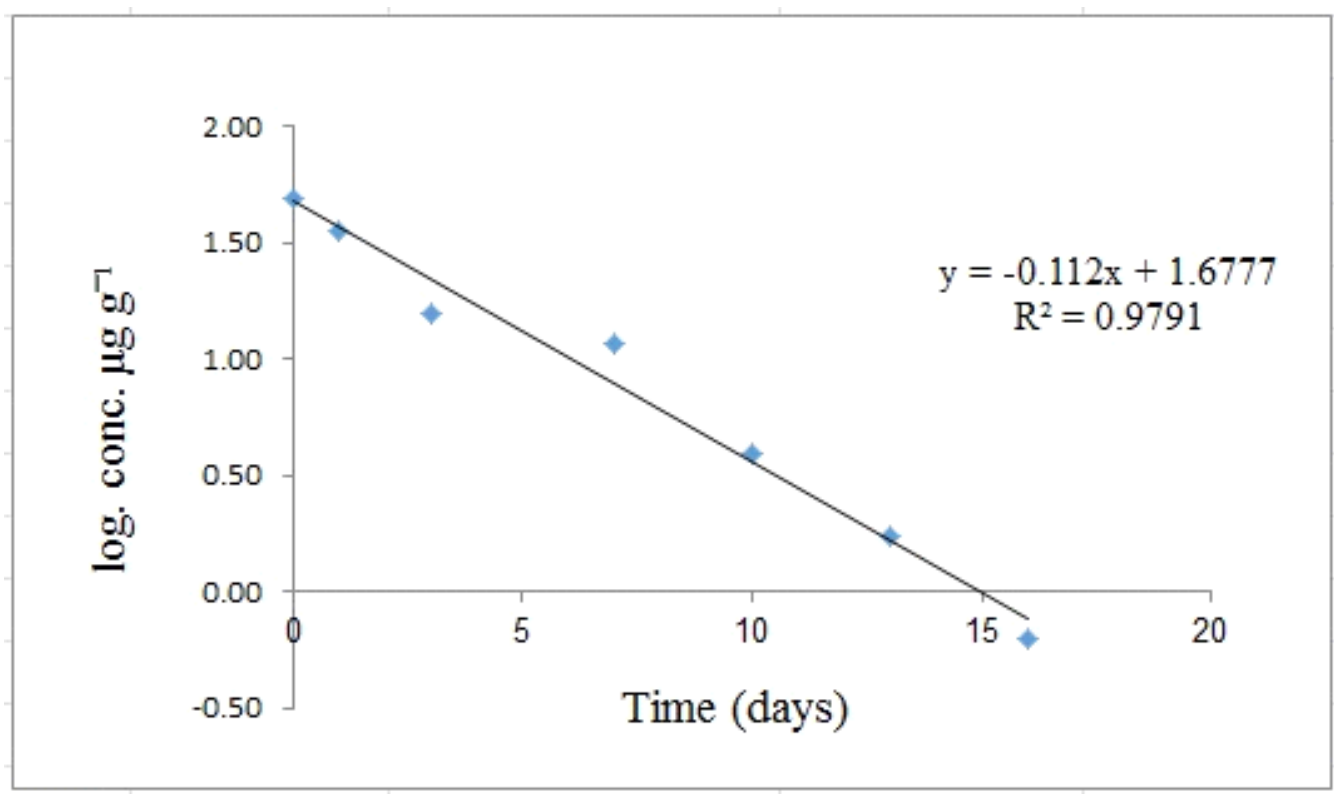

Fig. 4. Log. Residue - day regression lines of myclobutanil in/on grape fruits

\section{Residues of imidacloprid and myclobutanil on surrounding soil}

Residues and degradation percentages of insecticide imidacloprid and fungicide myclobutanil on surrounding soil under canopy after successive field applications are shown in Table (4) and Figs. (5 and 6). The initial residue deposits, determined on soil two hours after treatment were 0.98 and
$4.60 \mathrm{mg} \mathrm{kg}^{-1}$, respectively. These amounts decreased to 0.72 and $4.32 \mathrm{mg} \mathrm{kg}^{-1}$ one day recording degradation percentages of 26.51 and $6.09 \%$ for the same targeted pesticides, respectively. The longer the time after application, the higher the degradation and vice versa. A steady increase in degradation percentages occurred by the progression of time uptill the third week. Pesticide residues were gradually decreased to reach 0.65 , 
$0.56,0.52,0.49,0.41$ and $0.30 \mathrm{mg} \mathrm{kg}^{-1}$ corssponding degradation percentages of $33.47,42.37$, 46.98, 50.87, 58.03 and $69.50 \%$ (Imidacloprid), and $3.81,3.52,3.31,3.00,2.01$ and $1.78 \mathrm{mg} \mathrm{kg}^{-1}$ corresponding degradation percentages of 17.17 , 23.48, 28.04, 34.78, 56.30 and 61.30\% (Myclobutanil) at 3, 7, 10, 13, 16 and 21 days, respectively. Examination of the considered criteria represented by the established regression lines, i.e. slope, degradation constant $(\mathrm{K})$ and $R L_{50}$ proved significant differences in persistence behavior of the imidacloprid and myclobutanil. The degradation constant $(\mathrm{K})$ values are 0.047 and 0.044 , respectively. Results in the same table clearly indicate faster degradation of both targeted pesticides in soil. In this respect, imidacloprid was rapidly dissipated than myclobutanil, showing the $R L_{50}$ of 11.56 and 15.74 days, respectively. In addition, the relative degradation of imidacloprid is 1.36 times than myclobutanil.

Results concerning the residues of insecticide imidacloprid and fungicide myclobutanil in soil was generally in agreement with many research workers. Scholz and Spiteller (1992) found that imidacloprid degradation was more rapid in soils with cover crops than in bare soils, with a $t_{1 / 2}$ of 48 and 190 days, respectively. And also, degradation on soil via photolysis has a $t_{1 / 2}$ of 39 days. In addition, the half-life of imidacloprid in the soil tends to increase as soil pH increases (Sarkar et al 2001). Field studies have produced a wide range in halflife values $\left(t_{1 / 2}\right)$ from 27 days (Miles, Inc., 1992; Mobay Chemical Corp., 1992). Thus, imidacloprid can persist in soil depending on soil type, $\mathrm{pH}$, use of organic fertilizers, and presence or absence of ground cover. The primary imidacloprid breakdown products in soil as reported by (Rouchaud et al 1996 a,b) are imidacloprid urea, 6-hydroxynicotinic acid, 6-chloronicotinic acid; $\mathrm{CO}_{2}$ is then formed from 6-chloronicotinic acid (Scholz K. and M. Spiteller 1992). On the other hand, field soil degradation studies (bare soil) were provided from four sites in Germany where applications were made at the end of May and the beginning of June. Using the residue levels of parent myclobutanil determined over the whole core sampled $(0$ to $20 \mathrm{~cm}$ soil layer), $\mathrm{DT}_{50}$ were estimated to be 9 to 58 days (EFSA 2010 REPORT).

Table 4. Residues of imidacloprid and myclobutanil detected on surrounding soil.

\begin{tabular}{|c|c|c|c|c|c|c|}
\hline \multirow{2}{*}{$\begin{array}{l}\text { Days after } \\
\text { treatment }\end{array}$} & \multicolumn{3}{|c|}{ Imidacloprid } & \multicolumn{3}{|c|}{ Myclobutanil } \\
\hline & $\begin{array}{c}\text { Residues } \\
\mathrm{mg} \mathrm{kg}^{-1}\end{array}$ & $\begin{array}{c}\text { Degradation } \\
\% \\
\end{array}$ & $\begin{array}{c}\text { Persistence } \\
\% \\
\end{array}$ & $\begin{array}{c}\text { Residues } \\
\mathrm{mg} \mathrm{kg}^{-1}\end{array}$ & $\begin{array}{c}\text { Degradation } \\
\% \\
\end{array}$ & $\begin{array}{c}\text { Persistence } \\
\% \\
\end{array}$ \\
\hline $\begin{array}{l}\text { Initial } \\
\text { (2 hrs) }\end{array}$ & 0.98 & - & 100 & 4.60 & - & 100 \\
\hline 1 & 0.72 & 26.51 & 73.49 & 4.32 & 6.09 & 93.91 \\
\hline 3 & 0.65 & 33.47 & 66.53 & 3.81 & 17.17 & 82.83 \\
\hline 7 & 0.56 & 42.37 & 57.63 & 3.52 & 23.48 & 76.52 \\
\hline 10 & 0.52 & 46.98 & 53.02 & 3.31 & 28.04 & 71.96 \\
\hline 13 & 0.49 & 50.87 & 48.13 & 3.00 & 34.78 & 65.22 \\
\hline 16 & 0.41 & 58.03 & 41.97 & 2.01 & 56.30 & 43.70 \\
\hline 21 & 0.30 & 69.50 & 30.50 & 1.78 & 61.30 & 38.70 \\
\hline $\mathrm{K}$ & \multicolumn{3}{|c|}{0.047} & \multicolumn{3}{|c|}{0.044} \\
\hline $\mathrm{RL}_{50}$ & \multicolumn{3}{|c|}{11.56} & \multicolumn{3}{|c|}{15.74} \\
\hline
\end{tabular}

ND: Not detected under limit of detection $\left(0.006 \mathrm{mg} \mathrm{kg}^{-1}\right)$. 


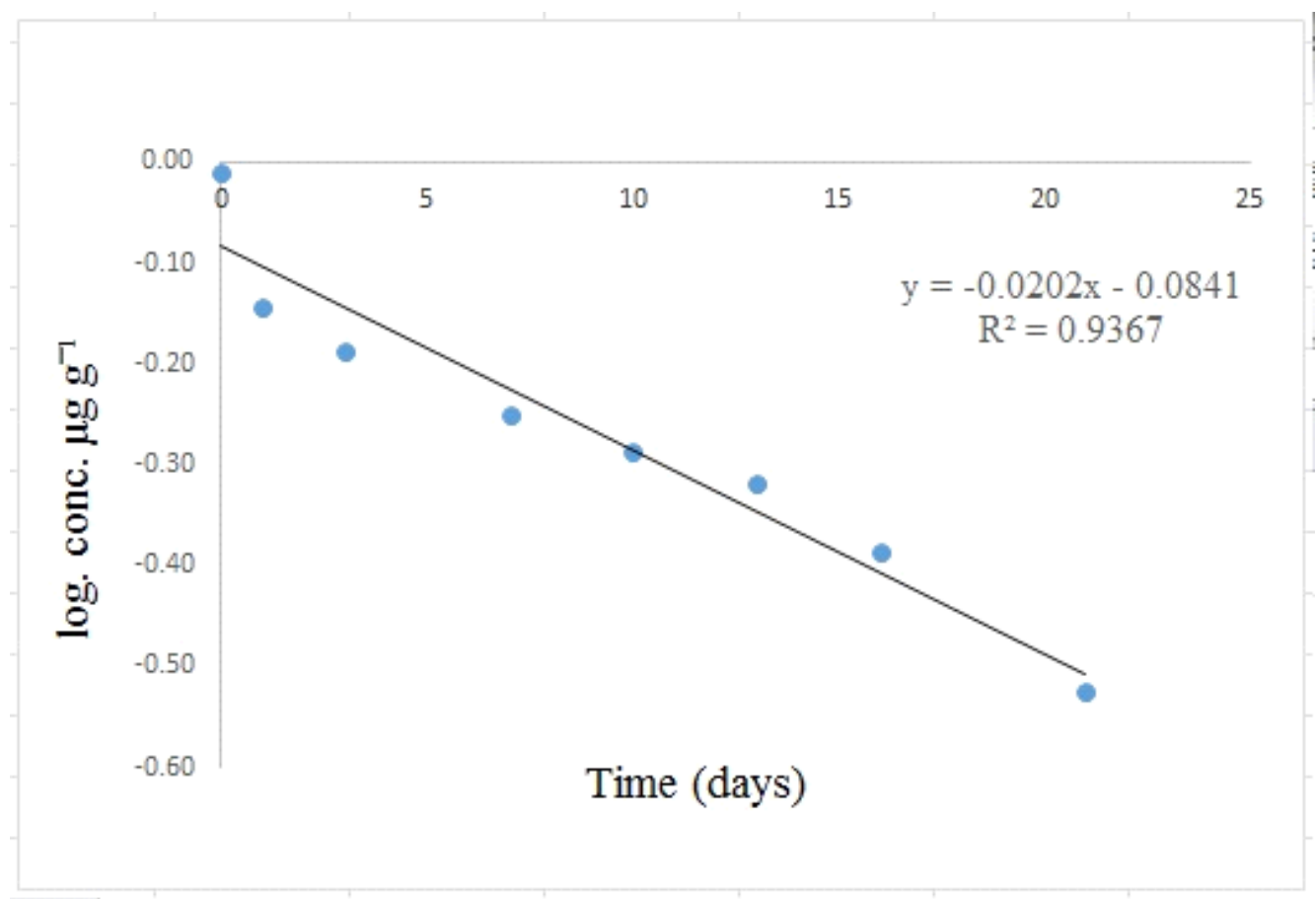

Fig. 5. Log. Residue - day regression lines of imidacloprid on surrounding soil

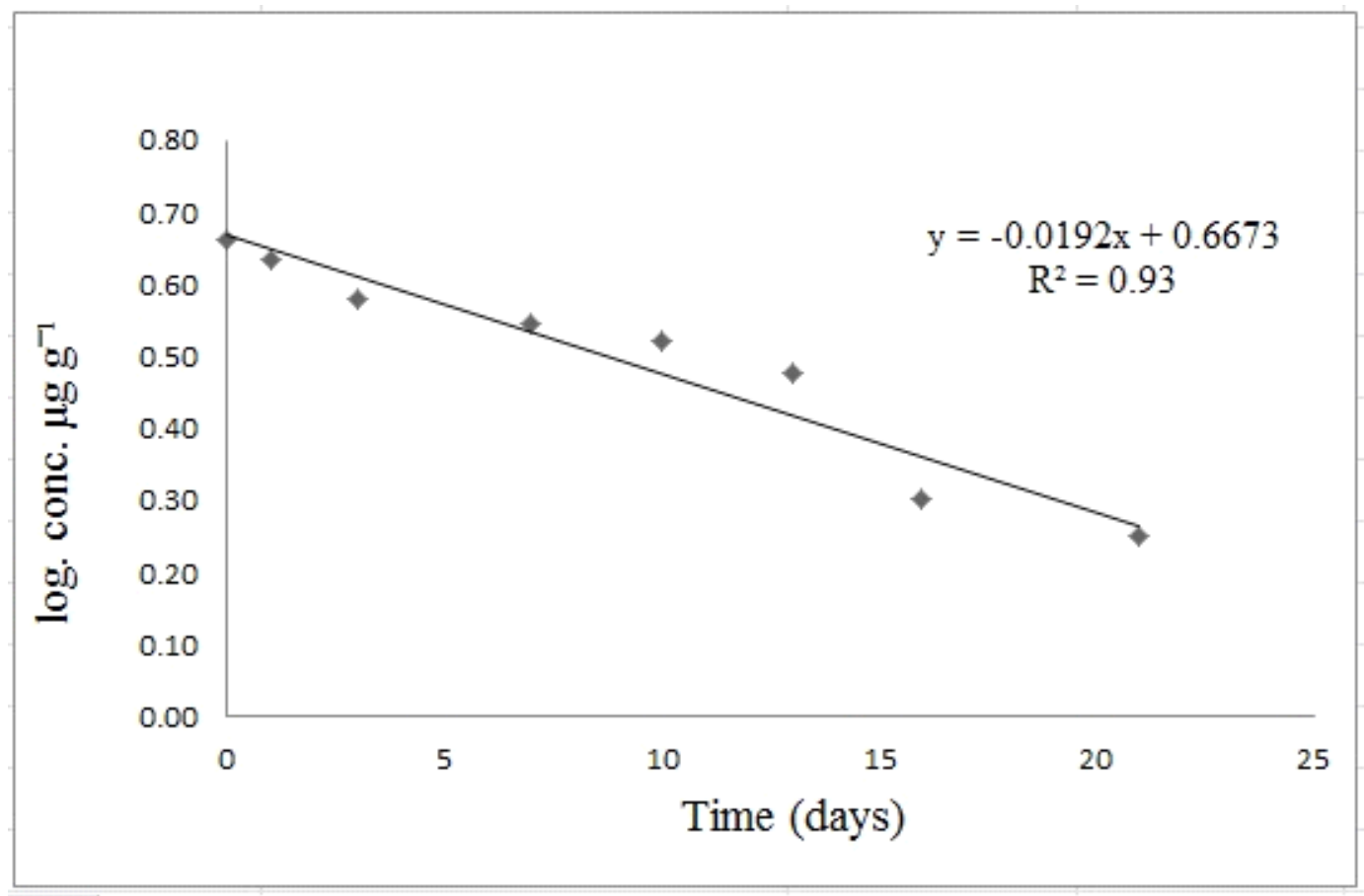

Fig. 6. Log. Residue - day regression lines of myclobutanil on surrounding soil 


\section{REFERENCES}

Ali A.A.I., Ashour M.B.A., Tohamy M.R.A. and Ragheb D.A. 2016. Azoxystrobin residues on tomato leaves and fruits. Zagazig J. Agric. Res., 42(6), 1547 - 1553.

Anastassiades M., Lehotay S.J., Stajnbaher D. and Schenck F. 2003. Fast and easy multiresidue method employing acetonitrile extraction/partitioning and "dispersive solid-phase extraction" for the determination of pesticide residues in produce. J. AOAC. Int., 86, 412-431.

Bonmatin J.M., Moineau I., Charvet R., Flecho C., Colin M.E. and Bengsch E.R. 2003. A LC/APCI-MS/MS Method for Analysis of Imidacloprid in Soils, in Plants and in Pollens. Anal. Chem., 75, 2027-2033.

Cherukuri S.R., Bhushan S.V., A.Reddy, H., Hymavathy M., Ravindranath D., Aruna M. and Rani M. 2015. Degradation Dynamics and Risk Assessment of Profenofos, Triazophos and Cypermethrin Residues on Tomato for Food Safety. International J. Agric. and Forestry, 5(1), 60-67.

Codex Alimentarias Commission 2013. Codex maximum limits for pesticide residues. Joint FAO/WHO Food Standard Programme. Vol. XIII. Ed. 2, Supp.1, FAO, Rome.

Cox L., Koskinen W. and Yen P. 1997. Sorptiondesorption of imidacloprid and its metabolites in soils. J. Agric. Food Chem. 45(4), 1468-1472.

Cox L., Koskinen W. and Yen P. 1998a. Changes in sorption of imidacloprid with incubation time. Soil Sci. Soc. Am. J. 62(2), 342-347.

Cox L., Koskinen W., Celis R., Yen P., Hermosin M. and Cornejo J. 1998b. Sorption of imidacloprid on soil clay mineral and organic components. Soil Sci. Soc. Am. J. 62(4), 911915.

Cox, L., Koskinen, W. and Yen, P. 1998c. Influence of soil properties on sorption-desorption of imidacloprid. J. Environ. Sci. Health. B33(2), 123-134.

Deng Z., Hu J., Qin D. and Li H. 2010. Simultaneous Analysis of Hexaconazole, Myclobutanil, and Tebuconazole Residues in Apples and Soil by SPE Cleanup and GC with NitrogenPhosphorus Detection. 71, (7), 679-684.

European Food Safety Authority, 2010. Conclusion on the peer review of the pesticide risk assessment. EFSA J. 8(10),1682.

Flores-Céspedes F., González-Pradas E., Fernández-Pérez M., Villafranca-Sánchez $M$., Socías-Viciana M. and Ureña-Amate M.D.
2002. Effects of dissolved organic carbon on sorption and mobility of imidacloprid in soil. $\mathbf{J}$. Environ. Qual. 31, 880-888.

Gomaa E.A.A and Belal M.H. 1975. Determination of dimethoate residues in some vegetables and cotton plant. Zagazig J Agric Res 2, 215219.

Grimalt S. and Dehouck P. 2016. Review of analytical methods for the determination of pesticide residues in grapes. J. of Chromatography A. 1433, 1-23.

Kamble S.T. and Saran R.K. 2005. Effect of concentration on adsorption of three termiticides in soil. Bull. Environ. Contam. Toxicol. 75, 1077-1085.

Miles, Inc. 1992. Premise termiticide - Environmental fate: Terrestrial field degradation for California site. Volume No. 51950-0032.

Mobay Chemical Corp. 1992. Premise termiticide - Environmental fate: Hydrolysis; Aqueous and soil photolysis. Volume No. 51950-0027.

Mohapatra S., Ahuja A.K., Sharma D., Deepa M., Prakash G.S. and Kumar S. 2011. Residue study of imidacloprid in grapes (Vitis vinifera L.) and soil. Quality Assurance and Safety of Crops \& Foods, 3, 24-27.

Ramadan M.M., El-Tantawy M.A., Ashour M.B.A. and Sherif R.M. 2016. Pyridalyl insecticide residues in tomato plants. Zagazig J. Agric. Res., 43(1), $245-250$.

Romeh A.A. and Hendawi M.Y. 2014. Degradation of fenpropathrin residues in squash fruits intercropped with garden rocket. Afr. J. Agric. Res., 9(3), 307-309.

Rouchaud J., Gustin F. and Wauters A. 1996a. Imidacloprid insecticide soil metabolism in sugar beet field crops. Bull. Environ. Contam. Toxicol. 56, 29-36.

Rouchaud J., Thirion A., Wauters A., Van de Steene F., Benoit F., Ceustermans N., Gillet J., Marchand S. and Vanparys L. 1996b. Effects of fertilizer on insecticide adsorption and biodegradation in crop soils. Arch. Environ. Contam. Toxicol., 31(1), 98-106.

Shady M.F.A., Hegazy M.E.A., Adam F.A., El-Baki M.A.A. and Shokr S.A. 2000. Persistence of malathion and prothiofos organophosphorus insecticides on and in some vegetable crops. Egyptian J. Agric. Res., 78(2), 605621.

Shalaby A.A. 2016. Residual behavior of abamectin and cyflufenamid in squash plants. Annals of Agric. Sci., Moshtohor., 54(4), 955-960. 
Sinha S.N., Rao M.V., Vasudev K. and Odetokun M. 2012. A liquid chromatography mass spectrometrybased method to measure organophosphorous insecticide, herbicide and nonorganophosphorous pesticide in grape and apple samples. Food Control, 25, 636-646.

Sleem, F.M.A. 2015. Persistence of some pesticides in and on some crops. Ph. D. Thesis. Fac. of Agric., Benha Univ., Egypt, pp. 8990.

Scholz K. and Spiteller M. 1992. Influence of groundcover on the degradation of ${ }^{14} \mathrm{C}$ - inidacloprid in soil. Proc. Brighton Crop Protection Conference - Pests and Dis. pp. 883-888.

Sarkar, M., Roy, S., Kole, R. and Chowdhury, A. 2001. Persistence and metabolism of imidacloprid in different soils of West Bengal. Pest Manag. Sci. 57, 598-602.

Sundaram B.S., Kookana R.S. and Naidu R. 1999. Degradation of bifenthrin, chlorpyrifos and imidacloprid in soil and bedding materials at termiticidal application rates. Pestic. Sci. 55, 1222-1228. 